\title{
Assessment of the age range, where juvenile $T$ inversion pattern in right precordial leads of an ECG changes to the adult upright $T$ wave pattern
}

\author{
M P B Goonetilleke ${ }^{1}$, U A Jayarathna ${ }^{2}$, P M W Madanayake ${ }^{2}$, H A M Inthisar ${ }^{2}$, D R Palangasinghe Pa $^{2}$ \\ P S Hettiarachchi ${ }^{2}$, U K Egodage ${ }^{2}$, A D Y Gayan ${ }^{3}$, M D S A Dilrukshi ${ }^{4}$, P K Rakshitha Rukmal ${ }^{5}$
}

Sri Lanka Journal of Child Health, 2013; 42: 205-208

\begin{abstract}
Objective: To determine the age range, where juvenile $\mathrm{T}$ inversion pattern in right precordial leads (V1 to V4) in an ECG changes to the adult upright $\mathrm{T}$ wave pattern

Method: A descriptive cross-sectional study was done in children aged 5 years and above referred to the paediatric cardiology clinic, Teaching Hospital Karapitiya from January 2012 to April 2013. Inclusion criteria were: children with no cardiac lesion or a haemodynamically insignificant cardiac lesion after a full cardiac evaluation. The cohort was divided into six age groups and the presence of juvenile and adult ECG patterns were evaluated.
\end{abstract}

Results: A total number of 1039 children were enrolled. At the age of 13 years 50\% depicted both juvenile and adult ECG patterns. At the age range of $13-15$ years $78(60 \%)$ of a total of 130 showed the adult ECG pattern compared to $99(44.4 \%)$ of a total of 223 at $11-13$ years $\left(X^{2}=8.0 ; p=0.005\right)$. Even after 13 years of age the juvenile ECG pattern persisted in $30-40 \%$ of children.

Conclusions: Transition of the juvenile $\mathrm{T}$ inversion pattern in right precordial leads in an ECG to the adult upright $\mathrm{T}$ wave pattern occurs predominantly at the age range of 13-15 years. Presence of juvenile $\mathrm{T}$ inversion pattern in an ECG after 13-15 years can be a normal finding as well as may be a pre-symptomatic diagnosis of a cardiomyopathy. Although it is normal to have a juvenile ECG pattern above 13 years it is advisable to perform an echocardiographic evaluation on children above 13 years with juvenile $\mathrm{T}$ inversion pattern which may lead to early diagnosis of cardiomyopathy.

(Key words: Juvenile T inversion pattern; Adult upright $\mathrm{T}$ wave pattern; ECG)

${ }^{1}$ Consultant Paediatric Cardiologist, ${ }^{2}$ Medical Officer, Paediatric Cardiology Unit, ${ }^{3}$ Intern Medical Officer, ${ }^{4}$ Pre-Intern, Teaching Hospital, Karapitiya, ${ }^{5}$ Final Year Medical Student, Faculty of Medicine, University of Ruhuna

(Received on 30 April 2013: Accepted after revision on 21 June 2013)

\section{Introduction}

At birth the right ventricle is larger than the left (RV dominance) due to high pulmonary vascular resistance (PVR) in utero ${ }^{1,2}$. This is manifested in the ECG as right axis deviation, tall $\mathrm{R}$ waves and upright $\mathrm{T}$ waves in the right precordial leads ${ }^{2}$. Within the first 7 to 10 days after birth the PVR drops dramatically and this is manifested as $\mathrm{T}$ inversions in the right precordial leads ${ }^{3,4}$. Therefore $\mathrm{T}$ waves in lead $\mathrm{V} 1$ to $\mathrm{V} 4$ invert after 7 days and typically remains inverted until at least 7 years ${ }^{5}$. Upright $\mathrm{T}$ waves in the right precordial leads (V1 to V4) between ages 7 days to 7 years is a potentially important abnormality and usually indicate right ventricular hypertrophy ${ }^{6}$.

Increase in systemic vascular resistance and the reduction in the PVR result in the left ventricle increasing in size until it is larger than the right ventricle by the age of 1 month ${ }^{1,7}$. By the age of 6 months the ratio of the right ventricle to the left ventricle is similar to that of an adult ${ }^{2,7}$. Therefore, as the child grows, the left ventricular dominant pattern becomes prominent and this is manifested as upright $\mathrm{T}$ waves in all the precordial leads, short $\mathrm{R}$ waves in the right precordial leads and tall $\mathrm{R}$ waves in the left precordial leads ${ }^{8}$. The usual transition age of the juvenile normal $\mathrm{T}$ inversion pattern of the right precordial leads to adult pattern is somewhat vague. Some studies have shown early transition at 7-9 years but others have shown late transition at 16-19 years ${ }^{9,10}$. No such studies have been conducted in a Sri Lankan child population so far. Lack of a clear consensus on this transition age range has caused many healthy children being referred for evaluation.

\section{Objective}

To determine the age range, where juvenile $\mathrm{T}$ inversion pattern in right precordial leads in an ECG changes to the adult upright $\mathrm{T}$ wave pattern

\section{Method}

A descriptive cross-sectional study was done in children 5 years and above referred to the Paediatric Cardiology Clinic, Teaching Hospital Karapitiya (THK), from January 2012 to April 2013. THK is the only tertiary care centre in the 
Southern Province of Sri Lanka and has a patient turnover of more than 400 patients per month. Random sampling method was used. Inclusion criteria were: any child who had no cardiac lesion or a haemodynamically insignificant cardiac lesion after cardiac evaluation by means of history taking, clinical examination and echocardiography. Those with haemodynamically significant cardiac lesions or identifiable syndromes proven to be associated with cardiac problems were excluded from this study since they can have an impact on the ECG. Children with a history of atypical type of syncope and those on any long term medications were also excluded from this study.

Informed written consent was taken from the parents or the guardians. A questionnaire including 5 sections was used for data collection. Section 1 focused on the reason for referral. Section 2 included patients' demographic data. Section 3 included full cardiovascular examination findings of the consultant paediatric cardiologist. Section 4 involved an echocardiographic evaluation by the consultant paediatric cardiologist to detect any cardiac anomalies. For this purpose an IE33 echocardiography machine was used. Section 5 included a 12 lead ECG evaluation with special emphasis on the $\mathrm{T}$ wave patterns of the right precordial leads.

An access database was created for data entry. After entering the data it was exported to Epi info $^{\mathrm{TM}}$ statistical analysis software for analysis.

\section{Results}

During the study period 1039 children 5 years of age and above were enrolled. The cohort was divided into 6 sets based on age (table 1). The ECG pattern was divided into adult and juvenile patterns (table 1). ECG pattern showing upright $\mathrm{T}$ waves in $\mathrm{V} 1$ to V4 or only inverted in V1 were considered as adult ECG pattern ${ }^{5,7}$. ECG patterns with $T$ wave inversions in leads $\mathrm{V} 1-\mathrm{V} 2, \mathrm{~V} 1$ to $\mathrm{V} 3$ or $\mathrm{V} 1$ to $\mathrm{V} 4$ were considered as juvenile patterns ${ }^{5,7}$.

Table 1

Distribution of adult and juvenile T inversion patterns

\begin{tabular}{|c|c|c|c|}
\hline Age & $\begin{array}{c}\text { Adult } \\
\text { pattern }\end{array}$ & $\begin{array}{c}\text { Juvenile } \\
\text { pattern }\end{array}$ & Total \\
\hline $5-7$ & $65(27.3 \%)$ & $173(72.7 \%)$ & 238 \\
\hline $7-9$ & $66(34.9 \%)$ & $123(65.1 \%)$ & 189 \\
\hline $9-11$ & $83(42.3 \%)$ & $113(57.6 \%)$ & 196 \\
\hline $11-13$ & $99(44.4 \%)$ & $124(55.6 \%)$ & 223 \\
\hline $13-15$ & $78(60.0 \%)$ & $52(40.0 \%)$ & 130 \\
\hline$>15$ & $45(71.4 \%)$ & $18(28.6 \%)$ & 63 \\
\hline
\end{tabular}

At the age range of 7-9 years 66 out of a total of 189 had the adult ECG pattern compared to 65 out of a total of 173 at $5-7$ years $\left(X^{2}=2.87 ; p=0.09\right)$. At the age range of $13-15$ years 78 out of a total of 130 had the adult ECG pattern compared to 99 out of a total of 223 at $11-13$ years $\left(X^{2}=8.0 ; p=0.005\right)$.

Percentage distribution of adult and juvenile patterns is shown in figure 1 .

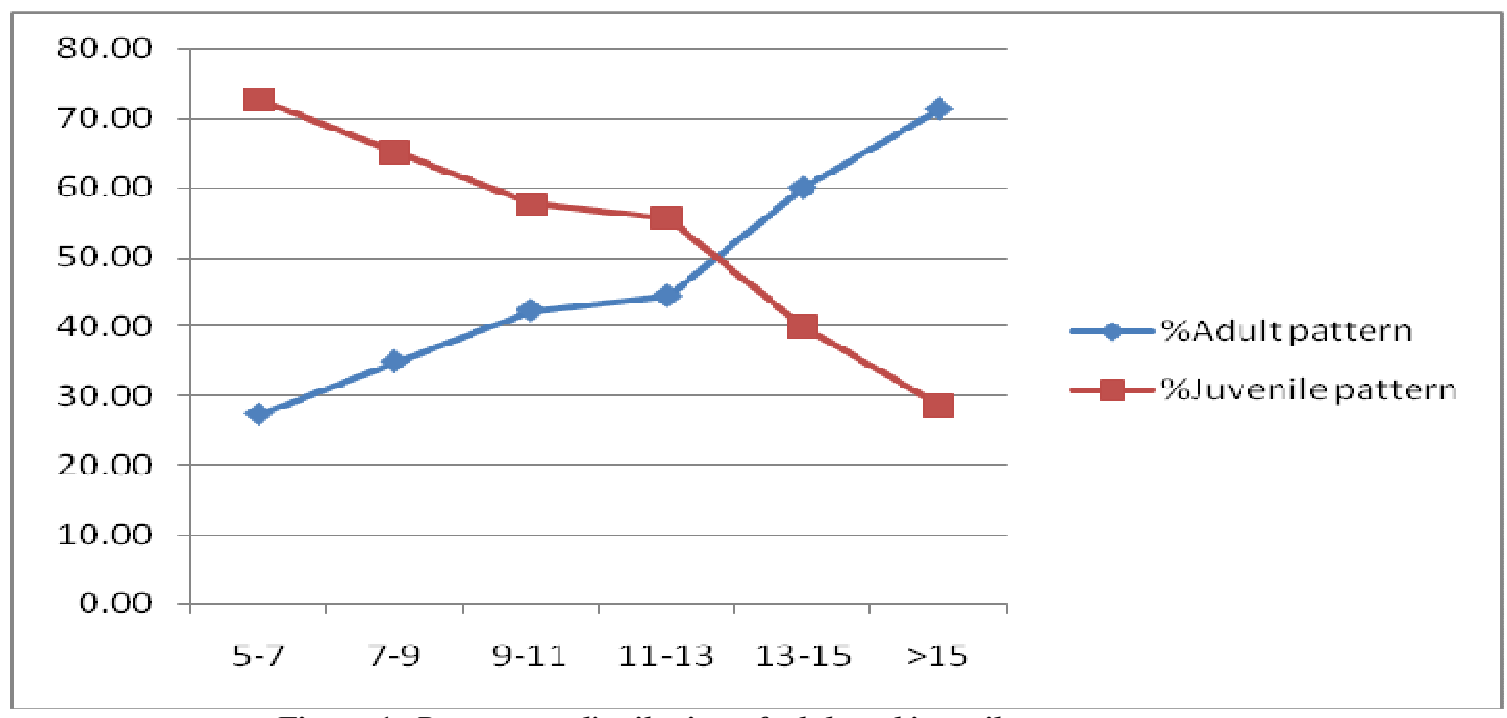

Figure 1: Percentage distribution of adult and juvenile patterns 
Figure 1 indicates a gradual increase in the adult pattern as one proceeds from the 5-7 year age group to the over 15 year age group. At the age of 13 years there are equal percentages of both juvenile and adult ECG patterns. After the age of 13 years the adult ECG pattern has overtaken the juvenile pattern. A striking feature is the significant rise in the number of children with the adult pattern within the age group of 13-15 years against the age group of 11-13 years. Thus, the adult ECG pattern is predominant within the age group of 13-15 years and above 15 years.

\section{Discussion}

As the child grows, the juvenile $\mathrm{T}$ inversion pattern in the right precordial leads gradually changes to the adult upright pattern ${ }^{5,6}$. However, this ECG pattern is also present in $0.1 \%$ to $3 \%$ of apparently healthy adults ${ }^{10}$. $\mathrm{T}$ inversion is a common ECG abnormality of inherited heart muscle diseases such as hypertrophic cardiomyopathy and arrhythmogenic right ventricular cardiomyopathy, which are leading causes of sudden cardiac death in young competitive athletes ${ }^{10,11}$. Persons of weight /height ratio less than $30 \%$ had higher incidence of juvenile $\mathrm{T}$ waves ${ }^{12}$.

The age this transition occurs is variable and most literature surveys give different age ranges ranging from 7-19 years ${ }^{5-10}$. Papadakis $M$ et al states that $\mathrm{T}$-wave inversions in $\mathrm{V} 1-\mathrm{V} 3$ are relatively common in athletes $<16$ years ${ }^{10}$ but was only $0.1 \%$ in those above 16 years. Miqliore F et al suggests that the prevalence of right precordial T-wave inversion decreased significantly with increasing age $(8.4 \%$ in those $<14$ years of age compared with $1.7 \%$ of children $\geq 14$ years of age) $)^{11}$. Echocardiographic investigation of children with post-pubertal persistence of $\mathrm{T}$-wave inversion at pre-participation screening is warranted because it may lead to pre-symptomatic diagnosis of a cardiomyopathy that could lead to sudden cardiac death during sports ${ }^{11}$.

This cohort of 1039 comprised healthy children with no cardiac lesions or haemodynamically insignificant cardiac lesions who were not on any long term cardiac medications. Therefore underlying cardiac lesion cannot affect the changes in ECG pattern. Distribution of case numbers is fairly uniform within different selected age groups which has added value to the accuracy of compared data among different age groups (table 1)

This study has shown $60 \%$ of children within the age group of 13-15 years showing an adult ECG pattern which is a $16 \%$ rise in the adult pattern compared to the $11-13$ year age group $\left(\mathrm{X}^{2}=8.0\right.$; $\mathrm{p}=0.005)$. Graph 1 illustrates that after 13 years the adult pattern predominates over the juvenile pattern. Therefore this study has shown a predominant transition from the juvenile to the adult pattern within the 13-15 year age group. This finding is in contrast to the findings in other studies which quote early transition at 7-9 years and a late transition of 16-19 years ${ }^{5-9}$. Despite the fact that the predominant ECG pattern after 13-15 years is the adult pattern juvenile ECG pattern can also persist in those above 13 years but the incidence gradually decreases over time according to graph 1.Therefore presence of juvenile $\mathrm{T}$ inversion pattern in an ECG after 13-15 years can be a normal finding as well as may be a pre-symptomatic diagnosis of a cardiomyopathy that could lead to sudden cardiac death during sports ${ }^{11}$.Therefore demonstration of persistence of T-wave inversion in children above 13 years justifies an echocardiographic investigation, which may lead to pre-symptomatic identification of early cardiomyopathy.

\section{Conclusions}

- Transition of the juvenile $\mathrm{T}$ inversion pattern in right precordial leads in an ECG to the adult upright $\mathrm{T}$ wave pattern occurs predominantly at the age range of 13-15 years.

- Presence of juvenile T inversion pattern in an ECG after 13-15 years can be a normal finding as well as may be a pre-symptomatic diagnosis of a cardiomyopathy that could lead to sudden cardiac death during sports.

- Although it is normal to have a juvenile ECG pattern above 13 years it is advisable to perform an echocardiographic evaluation on children above 13 years with juvenile $T$ inversion pattern which may lead to presymptomatic identification of early cardiomyopathy.

\section{References}

1. Geggel RL. Conditions leading to paediatric cardiology consultation in a tertiary academic hospital Pediatrics 2004; 114:409-17. http://dx.doi.org/10.1542/peds.2003-0898-L

2. Lue HC. The Report of Heart-Disease Screening in Taipei, Taiwan: CardiacChildren's Foundation of the Republic of China; 2006:2-7.

3. Chadha SL, Singh N, Shukla DK. Epidemiological study of congenital heart disease. Indian Journal of Pediatrics 2001; 68:507-10. http://dx.doi.org/10.1007/BF02723241 
4. Ino T, Yabuta K, Yamauchi K. Heart disease screening in Japanese children [letter]. British Medical Journal 1993; 306(6885): 1128. http://dx.doi.org/10.1136/bmj.306.6885.1128

5. Maroney M, Rantz L. Electrocardiograms in 679 healthy infants and children. Pediatrics 1950; 5:396.

6. Ziegler R. Electrocardiographic studies in normal infants and children. Springfield: Charles C. Thomas; 1951.

7. Strong WB, Downs TD, Liebman J, Liebowitz $\mathrm{R}$. The normal adolescent electrocardiogram. American Heart Journal 1972; 83:115-28. http://dx.doi.org/10.1016/00028703(72)90113$\underline{5}$

8. Davignon A, Rautaharju P, Boisselle E, Soumis F, Megelas M, Choguette A. Normal ECG standards for infants and children. Pediatric Cardiology 1979/80; 1:123-31. http://dx.doi.org/10.1007/BF02083144

9. Das BB, Ray M, Mohapatra SK, Das SP. Juvenile $\mathrm{T}$ waves (a study of 100 normal subjects). Indian Journal of Physiology and Pharmacology 1984; 28(4):291-8.
10. Papadakis M, Basavarajaiah S, Rawlins J, Edwards C, Makan J, Firoozi S, Carby L, Sharma S. Prevalence and significance of Twave inversions in predominantly Caucasian adolescent athletes. European Heart Journal 2009; 30(14): 1728-35.

http://dx.doi.org/10.1093/eurheartj/ehp164

11. Migliore F, Zorzi A, Michieli P, Perazzolo Marra M, Siciliano M, Rigato I, Bauce B, Basso C, Toazza D, Schiavon M, Iliceto S, Thiene G, Corrado D. Prevalence of cardiomyopathy in Italian asymptomatic children with electrocardiographic $\mathrm{T}$-wave inversion at pre-participation screening. Circulation 2012; 125: 529-38. http://dx.doi.org/10.1161/CIRCULATIONAH $\underline{\text { A.111.055673 }}$

12. Das BB, Ray M, Mohapatra SK, Das SP. Juvenile $\mathrm{T}$ waves (a study of 100 normal subjects) Indian Journal of Physiology \& Pharmacology. 1984; 28(4):291-8. 